\title{
La renta hídrica en el riego de cultivos extensivos en el norte de Buenos Aires (Argentina) ${ }^{*}$
}

\author{
DOI: https://doi.org/10.18046/recs.i33.4044
}

\author{
Water Rent in the Irrigation of Extensive Crops \\ in the North of Buenos Aires, Argentina
}

\section{Constanza Riera**}

Universidad de Buenos Aires, CONICET (Buenos Aires, Argentina)

\footnotetext{
* Resultados parciales de un proyecto de investigación en curso titulado "Moderna tecnología de riego para la producción de cultivos extensivos: las paradojas del uso agrícola del agua subterránea en la construcción social del riesgo en la cuenca del río Arrecifes" financiado por el Consejo Nacional de Investigaciones Científicas y Tecnológicas (CONICET) de Argentina con asiento en el Instituto de Geografía de la Facultad de Filosofía y Letras, Universidad de Buenos Aires (Argentina). Artículo de investigación recibido el 27.05.2020 y aprobado el 03.01.2021.

** Doctora en Antropología por la Facultad de Filosofía y Letras (FFyL), Universidad de Buenos Aires (Argentina) (2015); Magister en Estudios Sociales Agrarios, Facultad Latinoamericana de Ciencias Sociales (Flacso, Argentina) (2011). Docente del Departamento de Antropología, FFyL, UBA (JTP) (Argentina) y del Diploma Superior en Conflictos Ambientales y Planificación Participativa, Flacso (Argentina). Investigadora Asistente del CONICET, Instituto de Geografía, FFyL, UBA (Argentina).Correo electrónico: consriera@yahoo.com.ar ORCID: https://orcid.org/0000-0003-2379-5881
} 


\section{Cómo citar/How to cite}

Riera, Constanza (2021). La renta hídrica en el riego de cultivos extensivos en el norte de Buenos Aires (Argentina). Revista CS, 33, 275-299. https://doi.org/10.18046/recs.i33.4044 


\section{Resumen}

La concepción, culturalmente arraigada, de que el agua es un bien libre, desconoce que, en realidad, se trata de un recurso común que, en el caso de Argentina, es público. En este trabajo, me propongo revisar las teorías clásicas y algunas aproximaciones contemporáneas a la cuestión de la renta del suelo, para aplicarlas al uso del agua subterránea por parte de agricultores y empresas semilleras en el norte de la provincia de Buenos Aires. Con base en este estudio de caso, se argumenta que el uso del agua para riego, como un medio de producción no producido, implica, mediante la ausencia de regulación efectiva, la apropiación de una renta territorial. Para comprender su existencia y apropiación, es necesario considerar las diferencias entre los recursos agua y tierra. Como conclusión, se sostiene la existencia de una renta hídrica como la renta particular de la agricultura bajo riego mecanizado del capitalismo agrario.

\section{PALABRAS CLAVE:}

agua subterránea, regulación, apropiación, capitalismo

The culturally rooted conception that water is a free good does not acknowledge that it is a common-pool resource, which, in the case of Argentina, it is public property. In this paper we review the classical theories and some contemporary approaches to the question of ground rent to apply this concept to the use of groundwater by farmers and seed companies in the north of the province of Buenos Aires. Based on this case study, we argue that the use of water for irrigation, as a non-produced means of production, implies, through the absence of effective regulation, the appropriation of a territorial rent. To understand its existence and appropriation, it is necessary to consider the differences between water and land resources. In conclusion we claim the existence of water rent as a particular type of rent in the irrigated agriculture of agrarian capitalism.

\section{KEYWORDS:}

Groundwater, Regulation, Appropriation, Capitalism 



\section{Introducción}

La renta territorial -como una retribución que obtienen los propietarios de la tierra en el proceso productivo- es un concepto que ha suscitado fervientes debates desde sus primeras formulaciones, con Ricardo (1961), hasta la actualidad (Caligaris; Pérez-Trento, 2012). Como concepto aplicado al caso argentino, se destacan los trabajos de Arceo (2003), Braun (1974), Iñigo Carrera (2007), y Rodríguez y Seain (2007). En la agricultura bajo riego, el uso del agua -superficial o subterránea-implica el uso de un medio de producción no producido apropiable y, por ello, hay implicados aspectos de renta territorial. Dicho uso va acompañado de inversiones de capital que hacen accesible el recurso ${ }^{1}$; con lo cual, los precios de la tierra que cuentan con riego -observables en los contratos de arrendamiento y en los convenios de producciónincluyen conceptualmente la retribución al capital, en forma de interés invertido en la tierra. Pero ¿qué sucede con el agua, con el recurso que es puesto en producción a partir de la inversión en el sistema de riego? ¿Cómo es valorado o reconocido dentro de este proceso económico?

En este trabajo, se propone reflexionar sobre el caso de la explotación del agua subterránea para riego en el norte de la provincia de Buenos Aires, a partir de una revisión operativa de algunos conceptos básicos sobre la cuestión de la renta de la tierra o renta territorial. Dicha revisión está lejos de ser exhaustiva y tiene el exclusivo propósito de proveer las herramientas de análisis para el caso, sin pretender involucrarse en las discusiones teóricas de la compleja cuestión de la renta.

En el norte de la provincia de Buenos Aires (Argentina), se encuentra el Clúster de la Semilla, orientado a la producción de semillas -un specialty ${ }^{2}$ - para abastecer la producción nacional de granos y forrajeras, y también de su producción en contraestación, destinadas al mercado internacional (Riera, 2018). A pesar de situarse en la Pampa húmeda, zona núcleo de producción de granos del país, el riego es incorporado para el cultivo de semillas híbridas dentro de un elaborado sistema de producción que requiere procedimientos especiales vinculados al cruzamiento de variedades. En este, el riego es una herramienta fundamental para controlar las fechas de siembra y asegurar el rendimiento del cultivo, así como la calidad de la semilla a obtener.

Ante la falta de una regulación efectiva del recurso, en este trabajo se argumenta que el agua subterránea se privatiza en el momento de su consumo productivo,

1. En el caso del uso del agua subterránea, son las perforaciones encamisadas, bombas y equipos de aspersión.

2. O especialidad agrícola, que es un producto diferenciado con alto precio en el mercado, en oposición a commodity. 
implicando la existencia de una renta hídrica, que es apropiada por los dueños de los campos donde se instalan los sistemas de riego y por las empresas semilleras que tienen posiciones oligopólicas en el mercado de insumos agrícolas. Similares situaciones pueden observarse en otras partes del mundo, como España, México, Brasil y el Sudeste Asiático (López-Gunn, 2012; Mukherji; Shah, 2005; Sandoval, 2004; Villar, 2016), donde, a pesar de ser un recurso de propiedad estatal, el agua es extraída y utilizada en la agricultura comercial al margen de las regulaciones públicas.

En este contexto, resulta fundamental empezar a conceptualizar este uso y apropiación del agua en términos de renta, para dimensionar las implicancias de este reciente desarrollo del capitalismo agrario global que opera bajo una lógica de acumulación por despojo con la complicidad del poder estatal (Harvey, 2004). Se argumentará que, aunque el uso del agua no puede ser desanclado de la tierra irrigada, la caracterización de la renta en la agricultura bajo riego como hídrica es significativa como recurso teórico y metodológico, en tanto y en cuanto permite deconstruir el sentido común -ideológico- asociado al agua como un bien libre.

Desde el punto de vista metodológico, esta investigación se basó en una revisión bibliográfica de literatura clásica y contemporánea sobre la cuestión de la renta y sus aplicaciones en el contexto argentino. Por otro lado, los datos relativos al caso de estudio fueron construidos a partir de información primaria recabada durante sucesivos trabajos de campo realizados en la zona de estudio entre 2014 y 2018. Se realizaron observaciones en terreno, se participó en eventos del sector y se condujeron distintos tipos de entrevistas a productores agropecuarios, ingenieros agrónomos asesores en riego, empleados de empresas dedicadas a la producción de semillas, vendedores de equipos de riego, funcionarios locales, propietarios de campos y representantes de asociaciones del sector. El corpus de información primaria consiste en 36 entrevistas semiestructuradas y en profundidad, y notas de observaciones de campo, las cuales se transcribieron en forma de registros ampliados (Guber, 2001). Sobre estos registros, se realizó un análisis cualitativo mediante técnicas de codificación. El estudio del marco regulatorio del agua subterránea, por otro lado, implicó la recolección y análisis de fuentes secundarias, como leyes, resoluciones de organismos públicos, informes y artículos periodísticos.

A continuación, se presentan sucintamente algunas particularidades del caso, seguidas de la revisión de nociones básicas sobre la cuestión de la renta de la tierra, a modo de marco conceptual, para luego puntualizar las diferencias entre tierra y agua como recursos, ambos indispensables en el proceso de producción agrícola. En cuarto lugar, se considera la cuestión jurídica, en relación al papel del Estado y al manejo del agua en el riego productivo. Finalmente, en la conclusión, se argumenta en qué sentido es posible hablar de renta hídrica o, dicho de otro modo, cómo la 
explotación del agua subterránea da forma a la renta territorial en la producción de semillas híbridas de maíz en Argentina.

\section{El uso del agua subterránea en la producción de semillas híbridas}

En la región pampeana, el riego mecanizado por aspersión fue progresivamente incorporado, desde mediados de la década de 1990, para la producción de cultivos extensivos. En la provincia de Buenos Aires, según estimaciones del Programa Nacional de Agua (PN AGUA), del Instituto Nacional de Tecnología Agropecuaria (INTA), entre los años 2000 y 2015, la superficie bajo riego por sistema de aspersión y pivote central creció a una tasa anual de más de $18 \%$. Actualmente, en la zona norte de esta provincia hay casi 150 ooo hectáreas bajo riego (Figura 1).

FIGURA 1 Mapa de la zona norte de la provincia de Buenos de Aires con identificación de áreas regadas (2015)

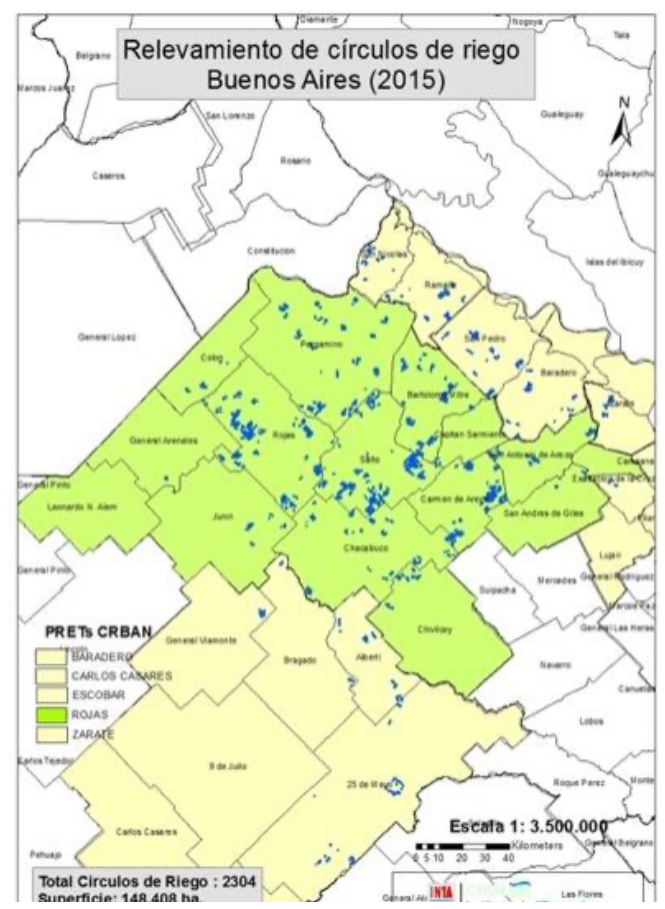


El agua de riego, usada de forma suplementaria a las lluvias, es extraída de los acuíferos Pampeano y Puelches, a través de pozos y perforaciones. El Pampeano es un acuífero libre más superficial que el Puelches, que es semiconfinado (Auge, 2004). Tradicionalmente, se extraía agua del acuífero Pampeano (y Puelches) mediante pozos sencillos y poco profundos que no discriminaban entre los distintos niveles del agua subterránea, denominados paperos por ser los que se construían para la producción de papa. Aunque las perforaciones que se realizan más recientemente son encamisadas y de una profundidad adecuada para alcanzar las aguas del Puelches, varios de los pozos paperos aún continúan activos.

Con respecto a los actores sociales que participan en la producción de semillas, en la fase de multiplicación de híbridos de maíz, se pueden identificar cuatro centrales: 1) las empresas que desarrollan las variedades, dueñas de la genética, mayormente de origen transnacional; 2) las empresas multiplicadoras que prestan servicio a las empresas que desarrollan las semillas; 3 ) los productores y dueños de los campos; y 4) los trabajadores estacionales contratados para la tarea de despanojado.

Independientemente de qué tipo de empresa se encargue del proceso de multiplicación -una empresa tercerizada o la misma semillera desarrolladora de la variedad (Riera, 2018)-, estas cuentan con dos formas de acceso a la tierra para realizar la multiplicación de las semillas hasta un nivel que permita abastecer la demanda: el arrendamiento y el convenio de producción. En el arrendamiento, el productor no está vinculado a la producción y se limita a cobrar el alquiler al inicio de la campaña agrícola. Si su campo no dispone de sistema de riego, las empresas se hacen cargo de la instalación del equipo. En ese caso, pagan al terrateniente entre 14 y 15 quintales de soja por hectárea, un precio equivalente al estipulado en el mercado de tierras de alquiler para la zona. En el caso de que el campo arrendado cuente con sistema de riego, ese monto se duplica, pagándose al terrateniente entre 30 y 35 quintales de soja por hectárea (Cuadro 1).

En la segunda forma, el convenio de producción, el productor se convierte en socio de la empresa semillera, a partir de un contrato de producción que se negocia al inicio de cada campaña. Al finalizar la misma, el productor, que en este caso también es el terrateniente, recibe como retribución un pago en dinero equivalente al rendimiento obtenido de maíz semilla, multiplicado por un coeficiente que busca equiparar el volumen final al de un maíz comercial. Dicho rendimiento se traduce en dinero según la cotización del cereal a precio pizarra en el momento del pago. El factor de multiplicación-del cual dependerá la valoración del rendimiento final del proceso productivo-es negociado todos los años en cada contrato e incluye, además del alquiler de la tierra, una estimación de los insumos invertidos por el productor, el costo de su trabajo y el de sus empleados (Cuadro 1). Los trabajadores estaciona- 
les son contratados exclusivamente para la tarea de despanojado por las empresas semilleras, por lo que el costo de esta mano de obra no forma parte del cálculo del coeficiente de multiplicación.

\begin{tabular}{|l|l|}
\hline CUADRO 1 & Formas de acceso a la tierra \\
\hline
\end{tabular}

\section{Arrendamiento}

El productor no está vinculado a la producción.

Contrato de alquiler fijado en quintales de soja, cobrados al inicio de la campaña.

Relación con el productor/dueño de la tierra

Forma contractual

\section{Convenio de producción}

El productor es socio del semillero.

Contrato de producción negociado al inicio de la campaña, cobrado al final.

Retribución por coeficiente de multiplicación: el rendimiento por hectárea efectivo (entre 2000 y $4000 \mathrm{~kg} / \mathrm{ha}$ ) se multiplica por un factor para que sea equivalente al rendimiento esperado promedio del grano comercial (entre 9000 y $14000 \mathrm{~kg} / \mathrm{ha}$ ) (capital + trabajo del productor + tierra).

Con riego: 30 y $35 \mathrm{q}$ de soja/ha (tierra + capital).
Con riego + manejo: US\$ 2 por milímetro regado por ha.

Fuente: elaboración propia con base en información de campo (2017).

La participación de estos tipos distintos de actores hace que existan redistribuciones entre categorías en el proceso de producción de semillas híbridas. En ese sentido, todo pago o ingreso por ceder el uso de la tierra que realizan los dueños de los campos aparece como renta, y establece el precio de la tierra; este puede incluir interés sobre el capital invertido en la tierra, parte de la ganancia media o parte del salario. Por lo tanto, lo que reciben los actores del proceso de multiplicación de la semilla está atravesado por las formas que tienen las empresas para acceder a la tierra y, con ella, al agua.

Mansilla (2006: 12) afirma que "para la economía clásica, la renta nace de las diferentes productividades del trabajo humano en diversas condiciones materiales". La incorporación de tecnología de riego tiene sentido dentro de una agricultura capitalista, porque expresa una productividad mayor con respecto a la agricultura 
de secano; o sea, aumenta la productividad de la tierra en relación con la posibilidad de disponer del agua en el momento deseado. ¿Cómo se traduce en términos de renta? Para introducirnos en esta cuestión, conviene revisar algunos elementos teóricos centrales.

\section{Algunas nociones básicas sobre la renta}

Las discusiones sobre renta de la tierra tratan de dilucidar analíticamente cómo se compone, conceptualmente, el pago que recibe el terrateniente, propietario de la tierra, por aportar el suelo-factor de producción indispensable en la agricultura-al proceso productivo. El concepto de renta viene de diversos autores, pero particularmente de Ricardo (1961:51), quien la definió como "aquella parte del producto de la tierra que se paga al terrateniente por el uso de las energías originarias e indestructibles del suelo". Esta definición fue retomada y discutida por Marx para complejizarla. Así, dicho autor advierte:

Desde un punto de vista práctico, se considera renta del suelo, naturalmente, todo aquello que el arrendatario paga al terrateniente en forma de canon por la autorización de explotar su tierra. Cualesquiera que sean los elementos integrantes de este atributo y las fuentes de que proceda, tiene de común con la verdadera renta del suelo el hecho de que es el monopolio ejercido sobre una porción del planeta el que permite al llamado terrateniente percibir este tributo, imponer este gravamen3. (Marx, 1959: 522)

En este pasaje de El capital, Marx distingue dos acepciones del concepto renta. Como se conoce comúnmente, es decir, lo que el sentido común llama renta, y la verdadera renta del suelo, que es la parte del valor resultante en la actividad productiva, que en agricultura es apropiada por el terrateniente por ser el propietario de la tierra, sin intervenir en el proceso productivo. Esta distinción alerta sobre el hecho de que no siempre todo lo que se paga al terrateniente por el uso de la tierra es una renta en el sentido económico. Dicha expresión monetaria también puede estar integrada por un canon, es decir, un monto que se impone gracias a la posesión monopólica del terrateniente sobre el recurso. Volveremos sobre esta cuestión más adelante.

A la verdadera renta, como observa Pierri (2011) citando a Ricardo (1961: 51), "a menudo se la confunde con el interés y la ganancia del capital”, lo que da lugar a nuevas distinciones sobre la composición de la renta. Para diferenciar los variados conceptos que intervienen en el pago que recibe el terrateniente, Marx llamó renta 
diferencial al concepto de renta de Ricardo (1961:54) "la diferencia entre el producto obtenido mediante el empleo de dos cantidades iguales de capital y trabajo". Esta es una primera forma de renta diferencial -usualmente llamada tipo I-, que refiere a la situación en que "esta ganancia extraordinaria se convierte en renta del suelo cuando dos cantidades iguales de capital y de trabajo se invierten con resultados desiguales en extensiones iguales de tierra" (Marx, 1959:544). Esta ganancia extraordinaria solo puede ser resultado de condiciones favorables de productividad creadas por la naturaleza en alguna de las extensiones de tierra y no en todas; condiciones como mayor fertilidad de algunos suelos, la ubicación o regímenes climáticos más adecuados para la producción agrícola de algunas locaciones.

De la renta diferencial I, Marx distingue una segunda forma de renta diferencial vinculada a una ganancia extraordinaria originada por una productividad mayor como consecuencia de una inversión de capital realizada por el arrendatario: "la renta se establece al arrendarse la tierra, con lo cual las ganancias extraordinarias obtenidas por las inversiones sucesivas de capital van a parar al bolsillo del arrendatario, mientras permanece en vigor el contrato de arriendo" (Marx, 1959: 565). Dicha ganancia extraordinaria, cuando es apropiada por el terrateniente -en general en forma de mejoras realizadas por el arrendatario al finalizar el contrato de arrendamiento-, configura una segunda forma de renta diferencial-también llamada renta diferencial II-. En general, corresponde a plusganancias resultantes de sucesivas dosis de capital en una misma tierra.

Finalmente, distinguió de estas dos formas de renta diferencial lo que llamó renta absoluta, que se caracteriza por su igual magnitud en todas las tierras y por sobrepasar al precio general de producción de la rama, derivada de la propiedad privada de la tierra:

dondequiera que las fuerzas naturales son monopolizables y aseguran al industrial que las emplea una ganancia excedente (...) nos encontramos con que la persona que por su título sobre una porción del planeta puede alegar derecho de propiedad sobre estos objetos naturales se apropia de esta ganancia excedente (...) en forma de renta. (Marx, 1959: 644)

Es decir, este último concepto expresa la ganancia extraordinaria basada en una fuerza natural apropiada de forma exclusiva, esto es, monopolizable y monopolizada. En palabras de Marx, la renta absoluta deriva de la propiedad territorial en tanto interfiera en el proceso de formación de la tasa media de ganancia:

pero la propiedad territorial, allí donde la producción necesita de la tierra absorbe una parte de la plusvalía, que de otro modo entraría en el juego de la compensación para formar 
la cuota general de la ganancia. La renta forma entonces parte del valory más concretamente del plus valor de las mercancías, con la diferencia que esta parte, en vez de ir a la clase capitalista, que se le ha extraido a los obreros, va a parar a los terratenientes que se la extraen a los capitalistas ${ }^{4}$. (Marx, 1959: 643)

La condición precedente supone, a su vez, el requisito de que la composición orgánica del capital, en esta rama, sea inferior a la media del conjunto de la economía.

Por lo tanto, para Marx, la renta de la tierra, como plusganancia basada en una fuerza natural monopolizable y monopolizada puede descomponerse en:

- Renta absoluta

- Renta diferencial I: forma que consiste, en general, en las diferencias de productividad entre dosis iguales de capital en diferentes tierras.

- Renta diferencial II: aquella que, también en general, corresponde a las diferencias de productividad de sucesivas dosis de capital en una misma tierra.

Por ello, todo pago o ingreso por ceder su uso aparece como renta (forma el precio de la tierra), y puede incluir interés sobre el capital invertido en la tierra, parte de la ganancia media o parte del salario. ${ }^{5}$ Cabe agregar que, para Marx, la renta diferencial I siempre es la base de la renta diferencial II. La tecnología incorporada a la producción como inversión de capital reconfigura las condiciones naturales -en tanto no producidas- originales:

partiendo de la misma fertilidad natural de las tierras, el grado en que esta fertilidad pueda hacerse disponible, dependerá, pues, en parte del desarrollo químico y en parte del desarrollo mecánico de la agricultura. La fertilidad, aunque constituya una cualidad objetiva de la tierra, económicamente implica siempre una cierta relación, desde el punto de vista económico, con el nivel de desarrollo de la química, y de la mecánica agrícola y varía conél. (...) La introducción de medios químicos (...) o de recursos mecánicos (...) pueden eliminar los obstáculos que en la práctica esterilizan tierras de fertilidad igual (...).

\section{Cursivas propias.}

5. De esta discusión surgió el problema de cómo se podría calcular la participación de la renta en el precio del producto, y a la inversa, cómo el pago al terrateniente puede comprenderse en relación con la dinámica de creación de valor de la producción agrícola. No es la intención de este trabajo adentrarse en esta cuestión, porque, además de ser algo aproximado e impreciso, no forma parte de los objetivos del mismo. Al respecto, Pierri (2011: 7) afirma que "ninguna publicación conocida ha calculado empíricamente y diferenciado los niveles de Renta Diferencial I y Renta Diferencial II que discriminarían la renta producto de las fuerzas indestructibles del suelo de aquella producto de mejoras en el suelo o en las condiciones de acceso a los mercados". 
Todas estas influencias que actúan sobre la fertilidad diferencial de distintas tierras se traducen en el hecho de que, por lo que se refiere a la fertilidad económica, el estado de la productividad del trabajo, que aquí equivale a la capacidad de la agricultura para explotar inmediatamente la fertilidad natural de la tierra-capacidad diferente según las diversas fases del desarrollo-, pesa tanto en la llamada fertilidad natural de la tierra como su composición química y sus otras cualidades naturales ${ }^{6}$. (Marx, 1959: 545-546)

De este modo, las condiciones materiales-originarias o no-se desarrollan junto con la técnica, el conocimiento y la inversión de capital, en una unidad (totalidad) que expresa diferencias de productividad. Como afirma Mansilla (2006: 13), "la renta es 'diferencial' ya que lo que la genera son las diferentes productividades de los recursos naturales y por ende, de la productividad del trabajo que utiliza esos factores en la producción". Para aplicar el concepto a la explotación de hidrocarburos, destaca la idea de renta de los recursos no producidos por el hombre-como el agua o el suelo- que tienen una retribución extraordinaria debido a esta condición que los ubica en una situación de escasez relativa. De modo que "la renta se define entonces como la 'ganancia extraordinaria' por sobre el costo de producción y la ganancia normal que es apropiada por el dueño de un recurso natural" (Mansilla, 2006: 13). En el caso particular de la agricultura bajo riego, el uso del agua también arroja diferencias de productividad. ¿Cómo participa entonces en la dinámica de creación de valor y la conformación de la renta?

\section{Diferencias entre tierra y agua como recursos productivos}

La concepción, culturalmente arraigada, de que el agua es un bien libre, desconoce que, en realidad, se trata de un recurso común que puede estar sujeto a distintos regímenes de propiedad, de los cuales ser de acceso abierto es solo uno de ellos (Feeny; Berkes; McCay; Acheson, 1990). Como recién se revisó, la cuestión de la propiedad/ apropiación de los recursos es central en la determinación de la renta. Incluso, como señala José Pierri (2011), estas ideas estaban presentes en Ricardo (1961):

no habrá renta pues nadie pagaría por el uso de la tierra cuando abundase la tierra no apropiada y disponible, por ende, para quienquiera pudiese optar por cultivarla.

Según los principios generales de la oferta y la demanda, no podría pagarse renta alguna por tales tierras por la razón enunciada, que explica por qué no se paga nada por el uso del agua y del aire. (64)

6. Cursivas propias. 
La naturalización -en el sentido antropológico de algo considerado como dado, una obviedad que invisibiliza las condiciones sociales de producción- que existe a propósito de la apropiación del agua como un bien libre dificulta la comprensión de las particularidades del recurso. Siendo un recurso común, el agua se caracteriza por la rivalidad y la no exclusividad. Rivalidad en tanto lo que es usado por uno, apropiado por uno, deja de estar disponible para otro; y no exclusividad en tanto es difícil excluir a potenciales usuarios (Orlove; Caton, 2009). La presencia simultánea de estas dos características que derivan de la materialidad del recurso (finito y fluido) es lo que distingue a los bienes comunes de otros recursos que, de igual modo, son factores de producción no producidos por el ser humano y que son escasos (Hardin, 1968; Ostrom, 1990). Estas características intrínsecas de los recursos comunes no deben confundirse con los regímenes de propiedad a los que los mismos pueden estar sujetos: acceso abierto, propiedad comunal, propiedad estatal y propiedad privada (Feeny et al., 1990). Dichos regímenes regulan el acceso y se limitan a ser la expresión jurídica de las relaciones sociales de producción que los atraviesan.

Sin embargo, tratada de un modo indiferenciado, incluso para Marx, la tierra comprende económicamente también al agua:

la renta diferencial se presenta en todas partes y se ajusta a las mismas leyes de la renta diferencial agricola dondequiera que existe renta. Dondequiera que las fuerzas naturales son monopolizables y aseguran al industrial que las emplea una ganancia excedente, ya se trate de un salto de agua, de una mina rica, de aguas abundantes en pesca o de solares bien situados, nos encontramos con que la persona que por su título sobre una porción del planeta puede alegar un derecho de propiedad sobre estos objetos naturales, se apropia esta superganancia y se la sustrae al capital activo, en forma de renta7. (Marx, 1959: 644).

En este sentido, que haya un propietario implica el monopolio sobre determinadas "porciones del planeta" como relación social de exclusión. En el ejemplo del salto del agua que usa Marx en el capítulo 38 de El capital, hay una concepción del recurso hídrico adherido a la tierra. El salto de agua es resultado del carácter fluido del agua y del relieve del suelo que adquiere la forma de energía hidráulica:

Esta condición natural la brinda la naturaleza solamente en ciertos sitios, sin que ninguna inversión de capital pueda inventarla allí donde no existe. No se halla vinculada a ciertos productos que el trabajo puede crear, como las máquinas, el carbón, etc., sino a determinadas condiciones naturales unidas a ciertas porciones del suelo. Los fabricantes que poseen saltos de agua excluyen a los que no los poseen del empleo de esta fuerza natural, porque

7. Cursivas propias. 
el suelo, y más aún el suelo dotado de saltos de agua, es limitado ${ }^{8}$. Lo cual no excluye que, aun siendo limitada la masa de los saltos de agua naturales de un país, pueda aumentarse la masa de la fuerza hidráulica utilizable para fines industriales. (Marx, 1959: 541)

Pero en el caso de otras formas en las que se presenta el agua, con su realidad múltiple (Stensrud, 2016), la no exclusividad derivada de su carácter fluido hace que no sea tan fácil delimitar y distribuir porciones, pues incluso en los casos en que sobra este recurso operan regímenes de propiedad privada. Además, el agua subterránea tiene especificidades físicas propias que refuerzan la no exclusividad del recurso, aun cuando, por su horizontalidad, tiene una ocurrencia distribuida, lo que implica, en principio, cierta equidad de acceso. Los agricultores pueden hacer pozos de riego con independencia unos de otros y sobre un área de extensión significativa, a diferencia del acceso a las fuentes de agua superficial, donde suele haber una puerta de acceso centralizada como en un dique o represa. Asimismo, el movimiento subterráneo del agua, al no ser libre, implica caudales relativamente lentos que no son observables de forma directa. Por ello, se afirma que es un recurso invisible que se encuentra bajo la superficie de la tierra, aunque no se sabe en qué magnitud, profundidad, ni dentro de qué límites. Estas características dificultan su gestión y control (Villholth; López-Gunn; Conti; Garrido; Van Der Gun, 2017).

A ello se le suma la diferencia jurídica entre suelo y agua, ya que, mientras el primero es objeto de propiedad privada, el segundo no, al menos formalmente en el caso de la legislación argentina y en la mayor parte del mundo, salvo algunas notables excepciones ${ }^{9}$. En Argentina, el agua es un bien público de propiedad estatal, por lo que vale la pena revisar ciertos supuestos vinculados a la renta territorial asociada a la propiedad privada y exclusiva del suelo. Me ocuparé de ello más adelante.

Sea propiedad pública o privada, el hecho de que la renta en la agricultura irrigada sea un tema poco estudiado se debe, posiblemente, a que, en las áreas bajo riego integral, la renta del suelo es insignificante, siendo predominante la retribución a la inversión de capital en términos de costosas infraestructuras de riego por canales de tal escala y complejidad que requieren del poder público centralizado para su ejecución (Palerm-Viqueira, 2009). En estos casos, el canon de riego expresa la inversión de capital en la infraestructura hidráulica, siendo poco relevante la renta del suelo propiamente dicha (Flichman, 1977). Pero ¿qué sucede con el fenómeno

\section{Cursivas propias.}

9. A pesar de los diversos y variados intentos de privatización de los recursos hídricos que tuvieron lugar durante la década de 1990, bajo el auge del neoliberalismo, la mayoría de las sociedades resistieron las presiones de privatización. El caso paradigmático de esta excepción es Chile, donde existe un mercado en el que se comercializan derechos de agua como bienes privados (Budds, 2012). 
relativamente reciente de agricultura bajo riego complementario que carece de dichas infraestructuras a gran escala?

La expansión de la agricultura irrigada con tecnologías mecanizadas que aprovechan las fuentes subterráneas se establece a partir de inversiones privadas de carácter individual, que son relativamente más fáciles de implementar y mucho menos costosas que las grandes infraestructuras de riego. Por eso, algunos autores lo denominan riego privado (Fraiture; Giordano, 2014). Ello ha dado lugar a una explosión en la puesta en uso del recurso hídrico subterráneo para la producción agrícola, no solo en Argentina, sino también en otras partes del mundo (Aeschbach-Hertig y Gleeson, 2012; Barnes, 2012; Budds, 2012; López-Gunn, 2012; Mukherji; Shah, 2005; Villar, 2016).

En el caso del riego complementario, si bien es necesaria una inversión para acceder al recurso hídrico, también es necesario que el recurso no producido esté disponible para su explotación. Entonces podría preguntarse, en términos de explotación de potencias naturales, en qué se diferencia la agricultura de secano, que aprovecha el agua de lluvia, de la de riego complementario, que utiliza las reservas subterráneas del acuífero. Una respuesta posible es que la diferencia radica en que el agua de lluvia no es monopolizable en el momento de la precipitación, mientras que el agua de los acuíferos sí, dado que el agua, además de fluida, es un recurso limitado: una cantidad finita circula dentro del ciclo hidrológico (Natenzon; González, 2012). Quien dispone de capacidad de inversión en infraestructura de riego para acceder al recurso subterráneo, lo deprime, y deja de estar disponible para quien no cuenta con dicha tecnología. Esto ha sucedido, por ejemplo, en el caso de las perforaciones que no tienen la misma profundidad que las de riego agrícola, ya sea para abastecer al ganado o a la población rural (Riera, 2018). Por lo tanto, el agua subterránea que se encuentra en reserva es monopolizable.

En este sentido, y en analogía con los saltos de agua, el agua subterránea es un recurso limitado, lo que da lugar a la rivalidad (lo que es utilizado o tomado por uno deja de estar disponible para otro); y no producido por el hombre (no puede ser creado por el capital), pero, a diferencia de los saltos, se caracteriza por la no exclusión que deviene de su naturaleza fluida intrínseca. Es, por lo tanto, algo distinto y separado de la tierra, con la que tiene una relación dinámica. Y estas diferencias tienen implicaciones para la configuración de un tipo particular de renta.

Por ello, en primer lugar, en la agricultura irrigada se puede mencionar la relación con la renta diferencial II que, por la inversión en obras de irrigación o, en este caso, en una tecnología mecánica relativamente fija, es la más clara. Como afirma Marx:

el capital puede unirse a la tierra, incorporándose a ella, de un modo más bien transitorio, como ocurre con las mejoras de carácter químico, los abonos, etc., o de un modo 
más bien permanente, que es el caso de los canales de desagüe, las obras de irrigación, los desmontes, los edificios de explotación, etc. (Marx, 1959: 518).

Las mejoras permanentes, producto de la inversión de capital, quedan adheridas a la tierra y redundan en diferencias de productividad con respecto a tierras que no poseen dichas mejoras. Como se vio anteriormente, en el caso de los contratos de arrendamiento, la inversión la hacen tanto la empresa semillera como el dueño de la tierra. Así, el riego forma parte de la composición de la renta. En el primer caso, es apropiada por la empresa semillera, en el segundo, por el terrateniente, al igual que en los convenios de producción. Gracias a la inversión en riego, se obtiene una mayor ganancia por la venta de más y mejores productos agrícolas.

Con respecto a la relación con la renta diferencial I, es necesario considerar la siguiente situación: si seguimos las premisas metodológicas propias del materialismo histórico, cuando Marx (1959: 520) señala que "la propiedad territorial, como todas las demás formas de propiedad de un modo definido de producción, ha de responder a una necesidad histórica transitoria y también, por consiguiente, a las relaciones de producción y de cambio que de él se derivan", cabe observar que, en el análisis de la renta de Marx, basado en la agricultura del siglo XIX, arrendatario y terrateniente son dos categorías de actores completamente distintos, con intereses contrapuestos, por los cuales entran en relaciones de contradicción ${ }^{10}$. Pero esta situación no es igual a la de este caso, donde principalmente es el terrateniente, productor y capitalista, quien hace la inversión, y el arrendatario es el semillero, una empresa con posiciones oligopólicas.

Ello hace que la distinción entre renta diferencial I y II sea problemática, o no relevante, en tanto que, si hay una ganancia extraordinaria por diferencias de productividad, esta es apropiada por el terrateniente, responda a condiciones originarias (no producidas) o no, lo que hace que pierda el sentido de clasificarla como de tipo II (Caligaris; Pérez-Trento, 2012).

Además, la renta diferencial II tiene como base la renta diferencial I que, por lo tanto, es su punto de partida. Como explica Marx,

la lógica hace que, a medida que va desarrollándose el cultivo intensivo, es decir, con las sucesivas inversiones de capital en la misma tierra, son preferentemente las tierras

10. "La renta se establece al arrendarse la tierra, con lo cual las ganancias extraordinarias obtenidas por las inversiones sucesivas de capital van a parar al bolsillo del arrendatario, mientras permanece en vigor el contrato de arriendo. De aquí también la lucha de los arrendatarios por conseguir contratos a largo plazo, y a la inversa, la multiplicación de los contratos rescindibles anualmente (tenancies at will) por la prepotencia de los terratenientes" (Marx, 1959: 565). 
mejores las que sirven de base a estas inversiones o aquellas en que éstas se realizan en grado mayor. (No nos referimos a las mejoras de carácter permanente por medio de las cuales se convierten en base eficaz de cultivo tierras antes inútiles). (...) Son las tierras mejores las que se eligen para ello, porque son las que ofrecen mejores perspectivas de que el capital invertido en ellas resulte rentable: estas tierras contienen la mayoría de los elementos naturales de la fertilidad, que sólo se trata de poner en acción $n^{11}$. (Marx, 1959: 569)

Es esta lógica capitalista la que explica la alta inversión en riego mecanizado en las mejores tierras del país, y de las mejores del mundo dentro del núcleo maicero, reforzando un clúster vinculado a la producción de semillas (Programa de Servicios Agrícolas Provinciales; Unidad para el Cambio Rural; Ministerio de Agricultura, Ganadería y Pesca, 2013), el producto de mayor valor de la agricultura extensiva local.

Con respecto a quién se apropia de la plusganancia extraordinaria en la agricultura bajo riego, indudablemente una parte es retenida por el terrateniente, siendo la producción de semillas bajo riego un negocio muy atractivo para el propietario de la tierra. Sin embargo, hay una particularidad en el uso del riego en el norte de Buenos Aires que se orienta casi exclusivamente a la producción de semillas, en su mayoría, híbridas de maíz. Como fue explicado, los arreglos de acceso a la tierra para la producción desanclan el producto final de especialidad (la semilla) y lo traducen en términos de commodities, a partir de un factor de multiplicación que equipara el rendimiento obtenido en semillas al rendimiento del maíz comercial. Esta operación incide en la conceptualización de la renta, porque el productor, cuando es además el dueño del suelo, queda excluido de la lógica de comercialización de la semilla. La ganancia extraordinaria la obtienen las empresas semilleras por su posición oligopólica, determinando, entonces, una plusganancia de monopolio. En este sentido, el precio de mercado puede ser aún mayor que el valor y esa sería una plusganancia de monopolio u oligopolio común y corriente no basada en el monopolio de una fuerza natural (Pedro Tsakougmakos, comunicación personal, 20.05.2019).

Por otro lado, se vio que, bajo un convenio de producción, se abonan al terrateniente y productor 2 dólares por milímetro regado por hectárea (Cuadro 1), y esto es lo que más llama la atención en esta relación, en términos del pago de un importe que tiene la particularidad de ser variable en razón del consumo de agua de riego. Se presume, a partir de este análisis, que ese valor por milímetro regado es una medida del consumo de energía para poner en funcionamiento el sistema de riego (sea a gasoil o energía eléctrica), un costo de la producción, e incluye un pago al trabajo del productor y sus empleados por el manejo del riego, pero no una valoración económica del agua. Algo similar plantea Mukherji (2007), para el caso de la India, a 
propósito de la explotación del agua subterránea para riego, un recurso no valorado monetariamente y regulado a través del control de la energía mediante mecanismos de mercado. Si existe una valoración económica del recurso hídrico subterráneo, en todo caso, se haya vinculado al canon de riego, como se verá a continuación.

\section{El papel del Estado y la regulación del agua como recurso común}

En Argentina, el agua es un bien público de propiedad estatal, administrado por las provincias. En la provincia de Buenos Aires, el uso productivo del agua para riego está regulado por la ley marco del Código de agua de 1999. Dicho código establece a la Autoridad del Agua (ADA) como encargada de la aplicación de dicha ley y, por lo tanto, es el organismo encargado de velar por el uso sustentable de los recursos hídricos provinciales.

Con dicho objetivo, las perforaciones para riego requieren una autorización para ser realizadas y un permiso de concesión para la explotación de las aguas. Sin embargo, la mayoría de las perforaciones son clandestinas (Riera, 2018), situación que genera reclamos, conflictos y preocupación entre agricultores vecinos y municipios por el agua subterránea, los cuales se hacen especialmente visibles en períodos de sequía, cuando el consumo de agua aumenta.

Ante esta situación, los usuarios del agua subterránea para riego, los productores y los semilleros, a través de sus asociaciones, desarrollaron mecanismos para legitimar el uso que ellos hacen del recurso. Esta legitimación consistió en tributar al Estado un canon por derecho de uso que se convirtió en su salvoconducto, ante la imposibilidad de tener las perforaciones en regla, ya que el pago en sí mismo no implicaba la legalización de las perforaciones (Riera, 2018). Así, la Asociación de Riego Pampeano (ARP) negoció el pago de 200 litros de gasoil por año por perforación, en 2013, y la Asociación de Semilleros Argentinos (ASA) acordó un pago de 5000 pesos por año por perforación en funcionamiento, en 2014.

A partir de la recaudación del canon, la ADA instrumentó un padrón de usuarios denominado Banco Único de Usuarios de Recursos Hídricos (BUDURH) y, en 2017, lanzó un programa de medidas para el reordenamiento del riego productivo que implicaba nuevos procedimientos administrativos, buscando mayor flexibilidad y aplicabilidad de las normas. En cualquier caso, durante todo este proceso, desde mediados de la década de 1990, el agua subterránea se viene usando de forma no regulada. Si bien se ha avanzado algo en esta materia, hoy en día, la declaración de 
las perforaciones, el pedido de permisos de explotación y el pago del canon dependen de la voluntad de los usuarios.

En este contexto de irregularidad, se suscitaron quejas, comentarios de vecinos, rumores, cosas que se dicen, mitos y hasta audios anónimos de WhatsApp que circulan entre los productores contando historias sobre problemas por el agua a causa del riego, que evidencian una competencia por el recurso. Según se explicó en otro trabajo (Riera, 2018), esta competencia se debe a una serie de factores, entre los que se encuentran: 1) persistencia de perforaciones paperas, que permiten extraer agua sin distinguir niveles ni fuentes de abastecimiento subterráneo; 2) ubicación de las perforaciones, que cuando están próximas a otras pueden provocar interacción por los conos de depresión que generan al ponerse en funcionamiento las bombas $\left.{ }^{12} ; y_{3}\right)$ disminución de disponibilidad en períodos de sequía, por menor reposición del acuífero.

Ante conflictos por el agua, la estrategia de los semilleros consiste, en primer lugar, en deslindar responsabilidades a los productores, dueños de los campos. Como explica un representante de ASA, "cada pozo es un activo físico del dueño del campo que debe registrar y a veces no lo hacen. Los productores de semillas que arriendan un campo con riego pagan únicamente el consumo de agua" (comunicación personal, 21.11.2016). Otra estrategia consiste en insistir en que las quejas son infundadas, ya que las fuentes de agua subterránea no están conectadas, puesto que las perforaciones de riego solo obtienen agua del acuífero más profundo; o explicar los problemas de las perforaciones desabastecidas como producto de la falta de mantenimiento o inversión. Cuando todo ello fracasa, los semilleros recurren a arreglos extrajudiciales que incluyen principalmente la reparación de los pozos desabastecidos con perforaciones de mayor profundidad o calidad constructiva.

Como vimos en la sección anterior, la propiedad es la relación social fundamental para la configuración de la renta y la distribución de las ganancias del proceso productivo. "Cualquiera que sea su forma específica, todos los tipos de renta coinciden en que la apropiación de la renta es la forma económica en que se realiza la propiedad territorial y en que, a su vez, la renta del suelo presupone la propiedad territorial, la propiedad de determinados individuos sobre determinadas porciones del planeta" (Marx, 1959: 529). El derecho de propiedad privada hace que el terrateniente reciba un pago por ceder el uso de la tierra:

12. Dos de los parámetros principales en el manejo del riego con agua subterránea son el nivel estático y el nivel dinámico del pozo de extracción. El nivel piezométrico estático es la profundidad subterránea a la que se encuentra el recurso cuando no hay bombeo ni extracción de agua. El nivel dinámico, en oposición, es la profundidad o nivel piezométrico al que se encuentra el recurso cuando los pozos están operando. Al encenderse la bomba e iniciarse la extracción, el plano donde se encontraba el recurso en el nivel estático desciende formando un cono de depresión o embudo hidráulico en el nivel freático en cuyo ápice se encuentra el pozo (Auge, 2004). 
este arrendatario capitalista paga al terrateniente, al propietario de la tierra explotada por él, en determinados plazos, por ejemplo, anualmente, una determinada suma de dinero contractualmente establecida (lo mismo que el prestamista del capital-dinero paga el interés estipulado) a cambio de la autorización que aquél le otorga de invertir su capital en este campo especial de producción. Esta suma de dinero recibe el nombre de renta del suelo ${ }^{13}$, ya se abone por una tierra, un solar, una mina, una pesquería, un bosque, etc. Se paga por todo el tiempo durante el cual el suelo haya sido cedido, arrendado contractualmente al capitalista por el terrateniente. (Marx, 1959: 517)

En el caso del agua, de propiedad pública, la existencia formal del canon de riego reconoce la presencia de esta renta. En el diccionario del español jurídico de la Real Academia Española, se define canon, en su acepción administrativa y financiera, como "renta o cantidad pagada de forma periódica a cambio de la utilización y disfrute de una cosa de propiedad pública". En este sentido, el canon es el pago por un derecho de uso. La distinción entre canon, como derecho de uso, y renta, en el sentido económico como ganancia extraordinaria apropiada por el propietario de la tierra, es engañoso. Esta cuestión jurídica está en el corazón de la renta territorial en Marx, como advierte:

este carácter común de las distintas formas de la renta-el de ser realización económica de la propiedad territorial y la ficción jurídica por virtud de la cual diversos individuos poseen de un modo exclusivo determinadas porciones del planeta- hace que pasen inadvertidas sus diferencias ${ }^{14}$. (Marx, 1959:530)

En el caso del aprovechamiento del agua subterránea, se confunde aún más. Por ser de propiedad pública, parafraseando a Marx, el Estado puede autorizar o denegar su utilización. El capital, por sí mismo, no puede crear reservas de agua subterránea, por consiguiente, la ganancia extraordinaria obtenida por el empleo de los acuíferos que realiza el capital requiere de la utilización de una fuerza natural monopolizable y monopolizada (Marx, 1959) ${ }^{15}$.

El Estado, al no cumplir en la práctica esta función de administración del agua subterránea, hace que el recurso público sea privatizado de hecho, transfiriéndose a

13. Cursivas propias.

14. Cursivas propias.

15. En la versión original, Marx (1959: 541) afirma: "pueden autorizar o denegar su utilización. Pero el capital de por sí no puede crear un salto de agua. Por consiguiente, la ganancia extraordinaria obtenida por el empleo de un salto de agua no nace del capital, sino de la utilización por éste de una fuerza natural monopolizable y monopolizada". 
los terratenientes - productores o simples dueños de campo-la posibilidad de cobrar renta por la explotación de un recurso monopolizable que, en ciertas circunstancias, es monopolizado, como se evidencia en la competencia puntual que existe por el recurso. Las relaciones sociales de producción, esto es, las relaciones de propiedad sobre los recursos son centrales para la configuración de la renta. A través de estas relaciones, se realiza la valorización del agua en la producción capitalista. En este sentido, si no hay regulación efectiva, hay privatización o, lo que es lo mismo, si no hay cobro del canon, hay apropiación de renta.

\section{Conclusión: en qué sentido es posible hablar de renta hídrica}

Las discusiones académicas vinculadas a las cuestiones teóricas sobre renta de la tierra eluden la dificultad de analizar problemáticas del presente (Pierri, 2011), como es el caso de la explotación del agua subterránea para cultivos extensivos. Esto, en sí mismo, es un desafío que conlleva una lectura crítica de los clásicos, reconociendo sus límites y lagunas (Bianchi, 2009).

Con respecto a esto, la primera cuestión que surge de este trabajo es la necesidad de distinguir entre renta del suelo y renta territorial, dado que lo territorial involucra una serie de recursos de diferentes características y propiedades que quedan confundidos en una gran abstracción cuando denominamos renta del suelo a la renta territorial. Como vimos en este trabajo con el agua, sus características (un recurso común, limitado y fluido) implican especificidades que intervienen en las relaciones sociales de producción concretas, que dan lugar a la renta. Como aclara Masilla (2006:12), "la renta no proviene de la naturaleza por sí misma, ni de las diferencias entre las productividades de los recursos. Todos los capitales hacen uso regularmente de las potencialidades naturales sin que eso genere renta. Para su existencia es necesario que las fuerzas de la naturaleza puedan ser apropiadas privadamente". Por mi parte, sostengo que esto es lo que sucede con el agua subterránea en la agricultura bajo riego, gracias a una regulación deficiente del organismo competente que, por lo tanto, no consigue ejercer su derecho de propiedad sobre el recurso, representando los intereses públicos.

Por eso, el riego con agua subterránea es una tecnología que tiende hacia la monopolización del recurso, evidenciando el avance del capitalismo sobre el agro y permitiendo la apropiación privada de un recurso sobre el que no era técnicamente posible disponer con facilidad hasta hace relativamente poco tiempo.

En este trabajo, se argumentó que hay elementos de renta cuando el agua subterránea utilizada para riego productivo es monopolizada en momentos de escasez 
hídrica -aunque de manera transitoria-, lo cual sucede al no respetarse el derecho de propiedad del Estado, privatizándose en el acto de producción/apropiación por ausencia de regulación.

A modo de síntesis de las hipótesis aquí presentadas, en primer lugar, cabe destacar que en la agricultura bajo riego del norte de Buenos Aires hay renta diferencial I, vinculada a las características del suelo apropiado por los terratenientes (productores o dueños de campo no vinculados a la producción), dado que donde se desarrolla el clúster se encuentran las mejores tierras del país. Pero también, y principalmente, hay involucrada una parte de renta diferencial II, por las diferencias de productividad que reporta la inversión en el sistema de riego-apropiadas por los productores o dueños de los campos cuando son ellos quienes realizan la inversión-.

Finalmente, se considera que, aunque el uso del agua no puede ser desanclado de la propiedad de la tierra, la caracterización de la renta en la agricultura bajo riego como hídrica es significativa como recurso teórico y metodológico, en tanto permite deconstruir el sentido común (ideológico) asociado al agua como un bien libre.

\section{Agradecimientos}

Agradezco a la Cátedra Libre Horacio Giberti, de la Facultad de Filosofía y Letras de la Universidad de Buenos Aires, por la invitación a presentar resultados de mi investigación sobre agricultura bajo riego en el marco del Seminario "Elementos actuales de la estructura agraria". Me encuentro especialmente en deuda con el profesor Pedro Tsakoumagkos quien tuvo la generosidad y paciencia de discutir conmigo varias de las ideas que aquí se presentan y de cuyo diálogo surge el presente trabajo. Como autora, soy única responsable de lo aquí expuesto.

\section{Referencias}

Aeschbach-Hertig, Werner; Gleeson, Tom (2012). Regional Strategies for the Accelerating Global Problem of Groundwater Depletion. Nature Geoscience, 5(12), 853-861.

Arceo, Enrique (2003). Argentina en la periferia próspera. Renta internacional, dominación oligárquica y modo de acumulación. Bernal: Universidad Nacional de Quilmes.

Auge, Miguel (2004). Regiones hidrogeológicas de la República Argentina y provincias de Buenos Aires, Mendoza y Santa Fe. La Plata: Asociación Latinoamericana de Hidrología Subterránea.

Barnes, Jessica (2012). Pumping Possibility: Agricultural Expansion through Desert Reclamation in Egypt. Social Studies of Science, 42(4), 517-538. 
Bianchi, Álvaro (2009). El marxismo fuera de lugar. Realidad Económica, 247, 73-97.

Braun, Osvaldo (1974). La renta absoluta y el uso ineficiente de la tierra en la Argentina. Desarrollo Económico, 14(54), 399-404.

Budds, Jessica (2012). La demanda, evaluación y asignación del agua en el contexto de escasez: un análisis del ciclo hidrosocial del valle del río La Ligua, Chile. Revista de Geografía Norte Grande, 52, 167-184.

Caligaris, Gastón; Pérez-Trento, Nicolás (2012). Para una historia crítica de la teoría: la renta diferencial de tipo II en retrospectiva. Trabajo presentado en ESHET Conference. Core and Periphery Countries: Lessons from Economic History and the History of Economic Thought, Ciudad de Buenos Aires.

Feeny, David; Berkes, Fikret; McCay, Bonnie J.; Acheson, James. M. (1990). The Tragedy of the Commons: Twenty-Two Years Later. Human Ecology, 18(1), 1-19.

Flichmann, Guillermo (1977). La renta del suelo y el desarrollo agrario argentino. Buenos Aires: Siglo XXI.

Fraiture, C. de; Giordano, M. (2014). Small Private Irrigation: A Thriving but Overlooked Sector. Agricultural Water Management, 131, 167-174.

Guber, Rosana (2001). La etnografía. Método, campo y reflexividad. Buenos Aires: Norma.

Iñigo-Carrera, Juan (2007). La formación económica de la sociedad argentina (Vol. I). Buenos Aires: Imago Mundi.

Hardin, Garret (1968). The tragedy of the commons. Science, 162, 1243-1248.

Harvey, David (2004). El nuevo imperialismo. Madrid: Akal.

López-Gunn, Elena (2012). Groundwater Governance and Social Capital. Geoforum, 43, 1140-1151.

Mansilla, Diego (2006). Una aproximación al problema de la renta petrolera en la Argentina (1996-2005). Realidad Económica, 223, 11-23.

Marx, Karl (1959). El capital (Tomo III). México: FCE.

Mukherji, Aditi (2007). The Energy-Irrigation Nexus and its Impact on Groundwater Markets in Eastern Indo-Gangetic Basin: Evidence from West Bengal, India. Energy Policy, 35(12), 6413-6430.

Mukherji, Aditi; Shah, Tushaar (2005). Groundwater Socio-Ecology and Governance: A Review of Institutions and Policies in Selected Countries. Hydrogeology Journal, 13, 328-345. https:// doi.org/10.1007/s10040-005-0434-9 
Natenzon, Claudia; González, Silvia (2012).El agua como problema social.Puente@ Europa, 10(2). Recuperado de https://puenteeuropa.unibo.it/article/view/4481

Palerm-Viqueira, Jacinta (2009). Regadío, origen del estado y la administración de sistemas hidráulicos: debate teórico y estudios de caso. En Aventuras con el agua (pp.179-192), editado por Jacinta Palerm-Viqueira; Tomás Martínez-Saldaña. Texcoco: Colegio de Postgraduados.

Pierri, José A. (2011). El concepto de renta en los clásicos aplicado al estudio del conflicto agrario del año 2008. Mundo Agrario, 11(22). Recuperado de http://sedici.unlp.edu.ar/ handle/10915/13502

Programa de Servicios Agrícolas Provinciales; Unidad para el Cambio Rural; Ministerio de Agricultura, Ganadería y Pesca (2013). Plan de Mejora Competitiva. Clúster de la Semilla. Buenos Aires: UCAR.

Orlove, Ben; Caton, Steven (2009). Water as an Object of Anthropological Inquiry. En The Question of Resilience: Social Responses to Climate Change (pp. 31-47), editado por Karen Hastrup. Copenhagen: R. Dan. Academy Sci. Lett.

Ostrom, Elinor (1990). Governing the Commons: The Evolution of Institutions for Collective Action. Cambridge: Cambridge University Press.

Ricardo, David (1961). Principios de economía política y tributación. Madrid: Aguilar.

Riera, Constanza (2018). Miedo, rumores y sanciones morales por el acceso al agua subterránea para riego en el Norte de la provincia de Buenos Aires (Argentina). Papeles de Trabajo, 12 (24), 204-223.

Rodríguez, J.; Seain, C. (2007). El sector agropecuario argentino, 1990-2005: del crecimiento con crisis a la exteriorización de la renta. En Transformaciones recientes en la economía argentina. Tendencias y perspectivas (pp. 57-78), coordinado por Karina Forcinito; Victoria. Buenos Aires: Prometeo.

Sandoval, Ricardo (2004). Participatory Approach to Integrated Aquifer Management: The Case of Guanajuato State, Mexico. Hydrogeology Journal, 12(1), 6-13.

Stensrud, Astrid (2016). Climate Change, Water Practices and Relational Worlds in the Andes. Ethnos, 81(1), 75-98. https://doi.org/10.1080/00141844.2014.929597

Villar, Pilar (2016). As águas subterrâneas e o direito à água em um contexto de crise. Ambiente \& Sociedade, 19(1), 83-102.

Villholth, Karen G.; López-Gunn, Elena; Conti, Kirstin I.; Garrido, Alberto; Van Der Gun, Jac (eds.), (2017). Advances in Groundwater Governance. London: CRC Press. 